\title{
Does segmental artery occlusion cause intravertebral cleft following osteoporotic vertebral fracture: a prospective magnetic resonance angiography study
}

\author{
Tianyu Zhang ${ }^{1}$, Yu Kang ${ }^{2}$, Yanhua Wang ${ }^{3}$, Peixun Zhang ${ }^{3,4}$, Dianying Zhang ${ }^{3,4}$ and Feng Xue S, $^{3 *}$
}

\begin{abstract}
Background: The avascular necrosis (AVN) hypothesis of intravertebral cleft (IVC) formation in osteoporotic vertebral fracture (OVCF) has received increasing attention. The aim of this article is to detect whether the segmental artery occlusion causes the IVC following OVCF.

Methods: Between December 2019 and April 2020, 44 OVCF patients with 46 fracture levels were prospectively enrolled and the vertebral segmental arteries were evaluated by magnetic resonance angiography (MRA). The artery conditions were divided into patent, narrow and occluded. The lesion segmental occlusion rate (LSOR) and the total occlusion rate (TOR) were calculated. The association of segmental artery occlusion and IVC formation was assessed.

Results: LOSR was $15.34 \%$ and TOR was $15.12 \%$. The segmental arteries of the unfractured vertebrae had a higher occlusion rate at thoracolumbar levels than at non-thoracolumbar levels. There was no significant difference between the IVC group and the non-IVC group in the fractured levels artery occlusion rate $(20.24 \pm 28.08$ vs $9.78 \pm 19.56$, $P=0.156)$ or the total segmental arteries occlusion rate $(13.83 \pm 12.04$ vs $11.57 \pm 9.25, P=0.476)$.

Conclusions: In patients with vertebral osteoporotic fracture, segmental artery occlusion is not associated with the development of intravertebral cleft.
\end{abstract}

Keywords: Intravertebral cleft, Osteoporosis vertebral compression fracture, Magnetic resonance angiography, Segmental artery occlusion

\section{Introduction}

Osteoporosis vertebral compression fracture (OVCF) is the most common osteoporosis fracture. Although conservative or minimally invasive treatment can always relieve pain, poor prognosis frequently occurs in OVCF patients combined with intravertebral cleft (IVC) $[1,2]$. IVC is the classic radiological sign of Kummell's disease [3], which is an area of low-intensity on T1-weighted and

*Correspondence: proxue@139.com

${ }^{3}$ Department of Traumatic Orthopaedics, Peking University People's Hospital, Beijing 100044, China

Full list of author information is available at the end of the article high-intensity or low-intensity on T2-weighted magnetic resonance images (MRI) in fracture vertebrae (Fig. 1b, c, d) [3]. The incidence of complications such as cement leakage [4], augmented vertebral recollapse (Fig. 1f, g) [5], and adjacent vertebral fracture [6] was high when OVCFs were combined with IVCs. Therefore, exploring IVC pathogenesis is important for preventing and finding better treatment methods.

The hypotheses of IVC formation are controversial, including the avascular necrosis (AVN) hypothesis [7], air formation hypothesis [8], biomechanical alteration hypothesis [9], and pseudarthrosis formation original author(s) and the source, provide a link to the Creative Commons licence, and indicate if changes were made. The images or other third party material in this article are included in the article's Creative Commons licence, unless indicated otherwise in a credit line to the material. If material is not included in the article's Creative Commons licence and your intended use is not permitted by statutory regulation or exceeds the permitted use, you will need to obtain permission directly from the copyright holder. To view a copy of this licence, visit http://creativecommons.org/licenses/by/4.0/. The Creative Commons Public Domain Dedication waiver (http://creativeco mmons.org/publicdomain/zero/1.0/) applies to the data made available in this article, unless otherwise stated in a credit line to the data. 

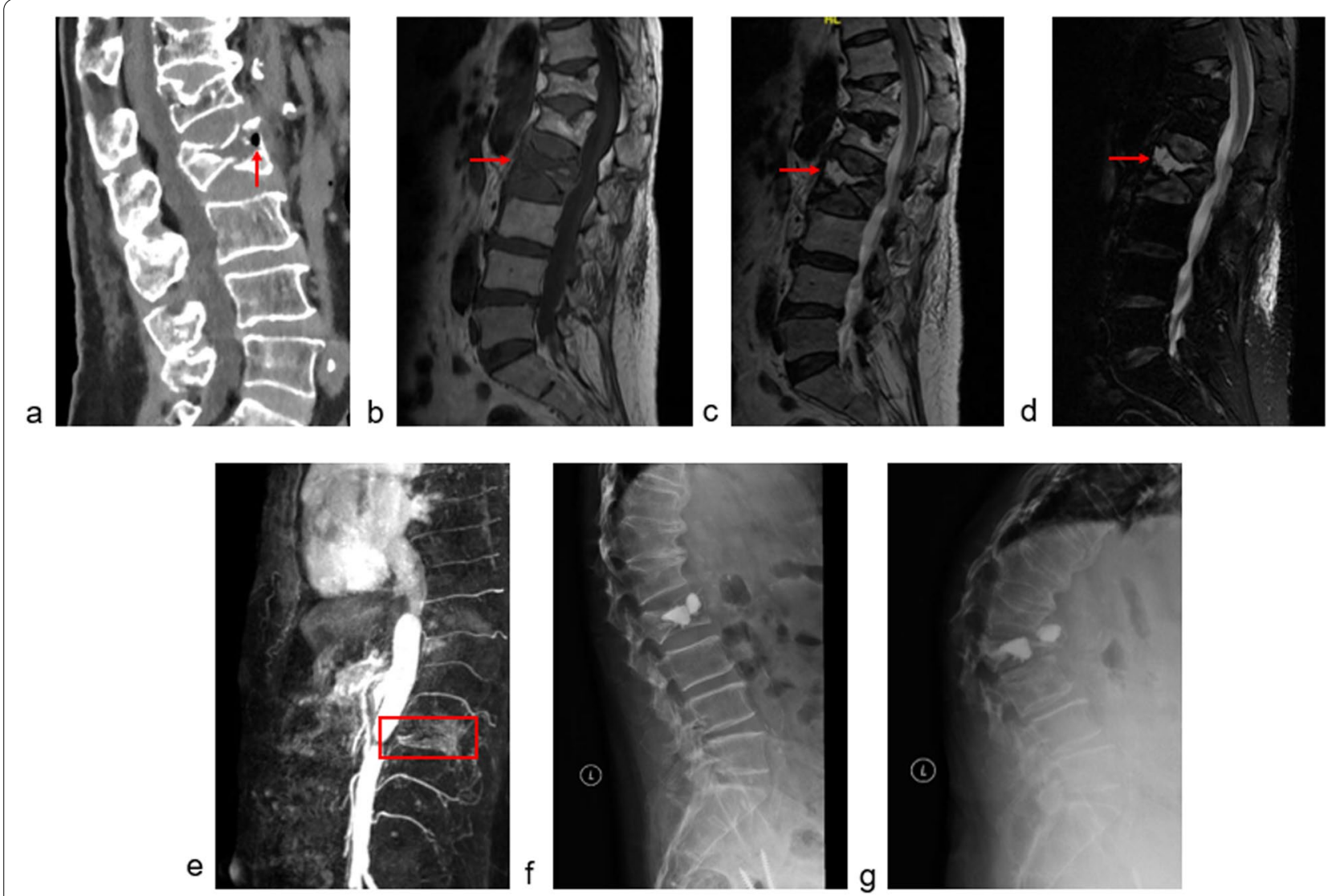

Fig. 1 An eighty-two-year-old female suffered from severe back pain for about 17 days (VAS 9) after left heavy object. CT showed an L2 compression fracture with intravertebral cleft formation (a) and MRI indicated an area of hypointensity on T1 and hyperintensity on T2 and T2-fat suppression images (b, c, d, red arrow). MRA revealed that both sides of the L2 segmental arteries were occluded (e). Unilateral vertebroplasty was performed for the patients $(\mathbf{f})$. The augmented vertebra collapsed and the cement was displaced half a year after the procedure (g)

hypothesis [10]. The AVN hypothesis received much attention among the above hypotheses. IVC is a sign of osteonecrosis caused by the destruction of blood supply $[11,12]$. There is growing evidence supporting this idea. Dupuy et al. [13] and Libicher et al. [7] both revealed that the pathological characteristic of IVC was avascular osteonecrosis by biopsy. Once vertebral compression fractures occur, the vertebrae require more blood supply for osteocytes growth and vertebral reconstruction [14]. If arteries cannot provide sufficient blood supply, osteogenesis might arrest, and vertebrae nonunion occur. Lin et al. [11] found that the IVC was related to poor perfusion of the adjacent vertebral bone marrow by dynamic contrastenhanced magnetic resonance imaging. Kim et al. [12] found a high artery occlusion rate in IVC patients by magnetic resonance angiography (MRA). However, due to the lack of a control group in Kim's study, segmental artery occlusion leading to the IVC could not be concluded. Therefore, we hypothesized that IVC patients would have a higher segmental artery occlusion rate than
non-IVC patients. The aim of this study was to elucidate the association between segmental artery occlusion and IVC formation (Fig. 1e).

\section{Methods}

The study was approved by the Ethics Review Committee of Peking University People's Hospital with approval number 2019PHB240. All the written informed consents were acquired from the patients.

\section{Patients}

We prospectively recruited 44 patients (male: female $=14: 30$ ) with OVCFs from the traumatic orthopedic department at a tertiary referral center. Recruitment was started in December 2019 with the completion of enrollment in April 2020. The inclusion criteria were as follows: 1) patients with osteoporosis vertebral compression fracture; 2) back pain over 1 week prior to starting intervention; 3) focal tenderness on the OVCF level; and 4) scheduled to receive vertebroplasty surgery. The 
exclusion criteria included 1) vertebral fracture caused by infection or malignancy; 2) neurological impairment; and 3) MRA contraindication. All patients underwent X-ray and MRA for the thoracic and/or lumbar spine during the first hospitalization.

\section{Sample size calculation}

For comparison of the segmental artery occlusion rate between the non-IVC group and IVC group, we calculated the sample size according to a previous study. A previous study revealed that the occlusion rate of the segmental artery in patients with IVC was 57.8\% [12]. The incidence of segmental artery occlusion in non-IVC patients was $19-27 \%$ [15]. Therefore, we assumed that the incidence of artery occlusion in the IVC group was $60 \%$ and that the segmental artery occlusion rate in the non-IVC patient was $30 \%$. The $\alpha$ was 0.05 and $\beta$ was 0.2 . The number of vertebral level in the IVC group and the non-IVC group was 1:1. The calculated sample size was as follows: the number of arteries in the non-IVC group was 40 , and the number of arteries in the IVC group was $40[16]$.

\section{Data collection}

Basic characteristics of the patients, including age, gender, body mass index (BMI), time from injury to MRI diagnosis, and fracture levels, were collected from the clinical files. Vertebral avascular risk factors were recorded to reflect the blood supply condition [17]. The number of factors including hypertension, diabetes mellitus, coronary heart disease, cerebral infarction, hormone usage, and smoking was regarded as the vertebral avascular risk factor score.

Imaging data including the X-ray or CT, MRI, and MRA results, were reviewed by the double-blind method. The IVC diagnosis and vertebral occlusion condition were separately assessed by two experienced surgeons. The compression rate (CR) was calculated according to previous study [4]. Fracture severity was graded as grade 1: mild $(<25 \%$ collapse); grade 2 : moderate to severe ( $>25 \%$ collapse) [5]. The diagnosis of IVC was based on the imaging sign of low-intensity on T1-weighted area and high-intensity or low-intensity area on T2-weighted MRI in fracture vertebra (Fig. 1).

According to the MRA image, each segmental artery condition was classified into patent, narrow and occluded and was scored as 1, 0.5, and 0, respectively (Fig. 2). The lesion segmental occlusion rate (LSOR) and the total occlusion rate (TOR) were calculated. The LOSR reflected the fracture level blood supply. LOSR $=(2-$ fracture level segmental artery occlusion condition score) $/ 2 \times 100 \%$. Except for L5, segmental arteries of each thoracic and lumbar vertebrae were in pairs [18]. Therefore, the L5 level was not included in the LOSR calculation. The TOR reflected the total spine blood supply. All MRAs covered T10 to L4 segments, and the corresponding artery conditions were recorded; therefore, the TOR was calculated using data from $\mathrm{T} 10$ to $\mathrm{L} 4$.

$$
\mathrm{TOR}=\left(14-\sum_{L 4}^{T 10} \text { segmental artery occlusion condition score }\right) / 14 \times 100 \%
$$

The compression vertebral segmental artery occlusion condition was assessed by an experienced surgeon and repeated with an interval of more than 1 month. The intraclass correlation efficiency in segmental artery occlusion was $0.788(P<0.001)$.

\section{Data analysis}

Patients were classified into the IVC group and the nonIVC group according to the diagnosis criteria. Age, gender, BMI, vertebral avascular risk factors, thoracolumbar levels (T11-L2), fracture severity, compression ratio, time from injury to MRI, LSOR and TOR were compared between the IVC and non-IVC groups.

\section{Statistical analysis}

Univariate analysis was analysed using SPSS Ver. 22.0 for Windows (IBM Corp. NY, USA). Continuous variables were analysed with chi-square tests and are presented as the mean \pm standard deviation. Categorical variables were analysed with Mann-Whitney $U$ tests and are presented as the median (IQR). The dichotomic variables were analysed with the Student's t-tests and presented as numbers (\%). $P<0.05$ was regarded as a significant difference.

\section{Results}

A total of 44 patients (male: female $=14: 30$ ) with 46 fractured vertebrae and 92 vertebral segmental arteries were included in this study. The mean age of the patients was $74.6 \pm 12.38$ years old. Twenty-one $(45.6 \%)$ compression vertebrae had IVC. The time from injury to MRI was $21 \pm 44.5$ days (Table 1 ). A total of 588 vertebral arteries were analysed by MRA. The total segmental artery occlusion rate was $15.34 \%$. Among the unfractured levels, artery occlusion or narrow rate of T10 was $20.9 \%$, T11 was $23.8 \%$, T12 was $34.3 \%$, L1 was $23.3 \%$, L2 was $8.4 \%$, L3 was $4.6 \%$, and L4 was $8.9 \%$ (Fig. 3).

The fractured vertebrae were $\mathrm{T} 5$ in 1 patient, T9 in 4 patients, T10 in 1 patient, T11 in 3 patients, T12 in 9 patients, L1 in 14 patients, L2 in 8 patients, L3 in 1 patient, L4 in 3 patients, and L5 in 2 patients. Among these, 42 vertebral segmental arteries were included in the IVC group and 50 in the non-IVC group. The time from injury to MRI was significantly different between 


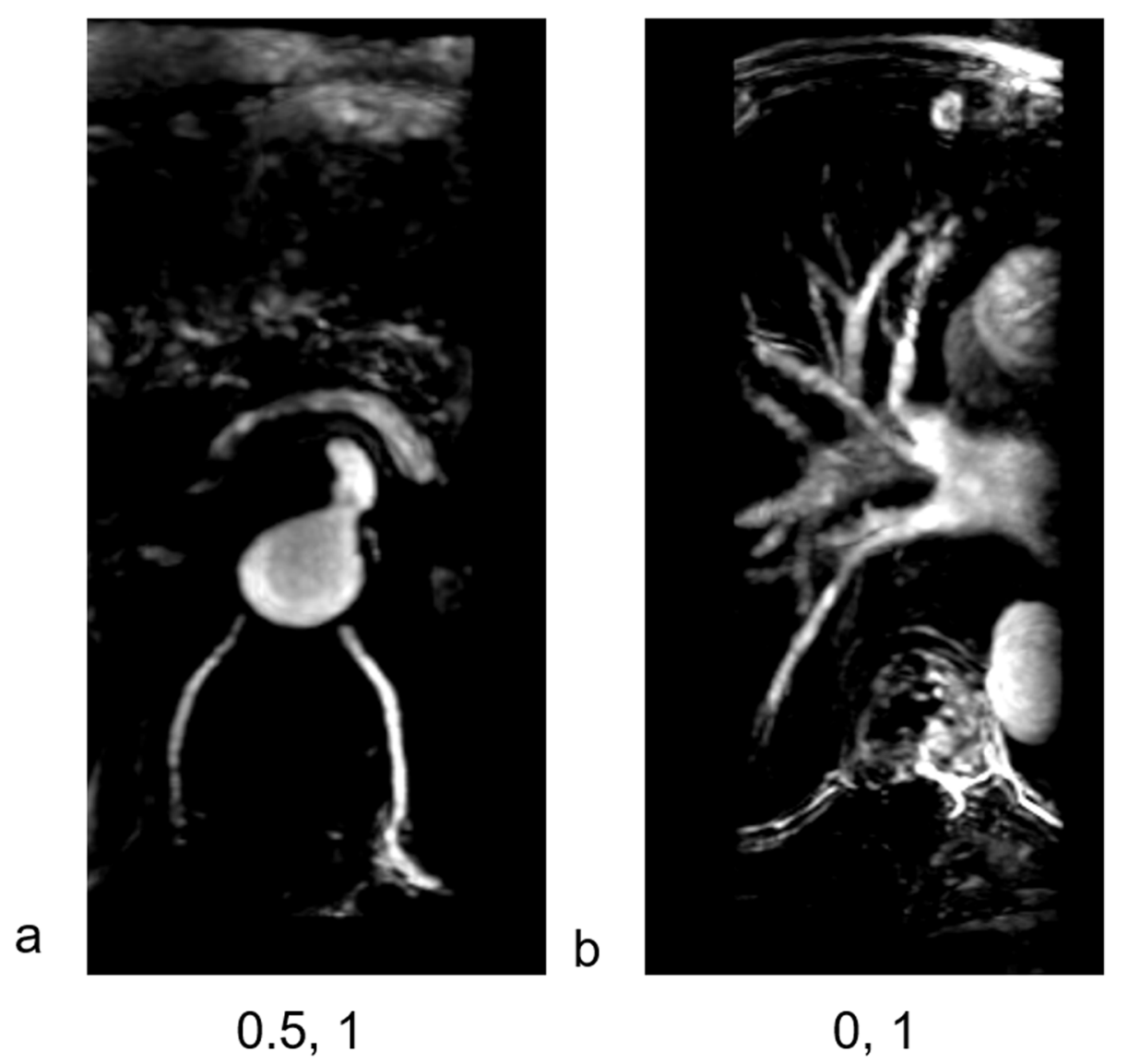

Fig. 2 Each segmental artery condition was classified into patent, narrow and occluded and was scored as 1, 0.5, and 0, respectively

Table 1 Characteristics of Patients

\begin{tabular}{ll}
\hline Variable & $\begin{array}{l}\text { Patients } \\
\text { number } \\
(\boldsymbol{n}=\mathbf{4 4})\end{array}$ \\
\hline Age (years) & $74.6 \pm 12.38$ \\
Gender (female) & $30(68.2 \%)$ \\
BMI (kg/m²) & $23.19 \pm 3.04$ \\
fracture severity (>25\% collapse) & $20(44.4 \%)$ \\
CR (\%) & $79 \pm 18$ \\
Time from injury to MRI (Days) & $21 \pm 44.5$ \\
Thoracolumbar levels (T11-L2) & $34 \pm 77.3$ \\
LSOR (\%) & 15.12 \\
TOR (\%) & 15.34 \\
\hline
\end{tabular}

$n$ patient number, $B M I$ Body mass index, $C R$ Compression rate, $L S O R$ Lesion segmental occlusion rate, TOR Total occlusion rate

$\mathrm{LOSR}=(2-$ fracture level segmental artery occlusion condition score) $/ 2 \times 100 \%$ )

TOR $=\left(14-\sum_{14}^{T 10}\right.$ segmental artery occlusion condition score $) / 14 \times 100 \%$.

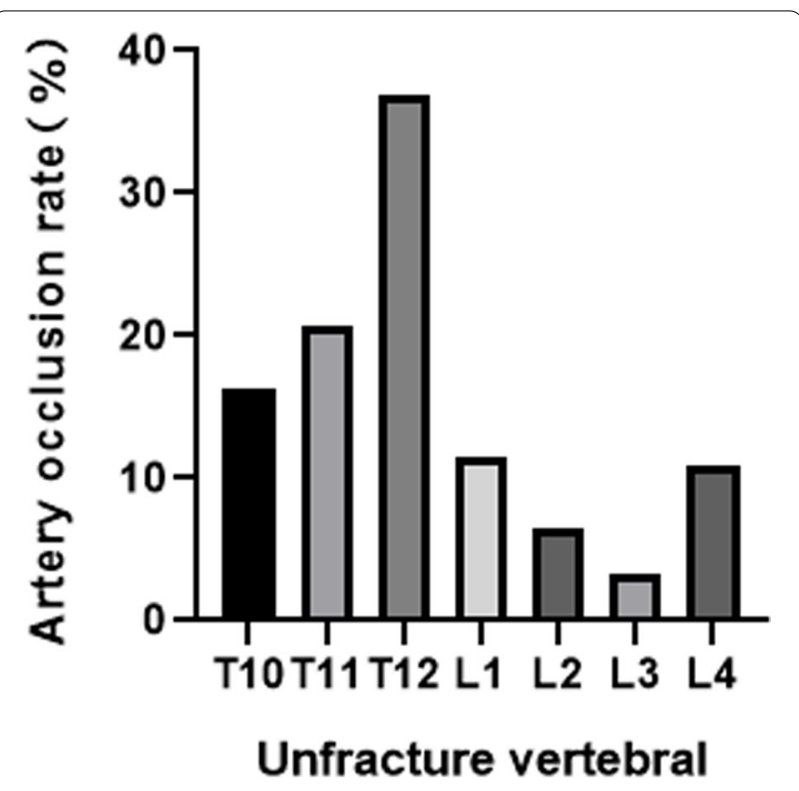

Fig. 3 Occlusion rate of each unfractured vertebral segmental artery 
the IVC group and the non-IVC group $(39.69 \pm 64.49$ vs. $9.07 \pm 12.18, P=0.041)$. There was no significant difference in age, gender, BMI, vertebral avascular risk factors, thoracolumbar levels (T11-L2), fracture severity, or compression ratio $(P>0.05)$. Neither the lesion segmental occlusion rate (LSOR) nor the total occlusion rate (TOR) showed significant difference between the IVC group and the non-IVC group (LSOR $20.24 \pm 28.08 \%$ vs. $9.78 \pm 19.56 \%$, TOR $13.83 \pm 12.04 \%$ vs. $11.57 \pm 9.25 \%$, $P>0.05$ ) (Table 2).

\section{Discussion}

IVC formation in OVCFs was significantly associated with poor prognosis [4-6]. However, the pathogenesis of IVC is still controversial. Whether segmental artery occlusion causes IVC has received much attention.

In this study, the LOSR and TOR were not significant different between the IVC group and the non-IVC group. LOSR reflected the local vertebral blood supply, and TOR reflected the whole vertebral blood supply. This study indicated that vertebral segmental artery occlusion was not associated with IVC formation.

In a previous study, Nambu et al. [19] showed that bilateral segmental artery ligation reduced vertebral blood perfusion. Lin et al. [11] found that adjacent vertebral marrow poor blood perfusion was associated with IVC formation. These two studies indicated causality between segmental artery occlusion and IVC. However, we concluded the contrary result. Collateral arteries formed to compensate for the vertebral blood supply when the segmental artery was occluded [18] (Fig. 4). Therefore, artery occlusion might not completely reflect

Table 2 Comparison of the IVC group with non-IVC group

\begin{tabular}{llll}
\hline Factors & IVC $(\boldsymbol{n}=\mathbf{2 1})$ & Non-IVC $(\boldsymbol{n}=\mathbf{2 5})$ & $\boldsymbol{P}$ values \\
\hline Age (years) & $76.48 \pm 12.46$ & $72.64 \pm 12.14$ & 0.297 \\
Gender (female) & $15(71.4 \%)$ & $17(68.0 \%)$ & 0.801 \\
BMI (kg/m²) & $22.72 \pm 3.10$ & $22.34 \pm 2.94$ & 0.486 \\
$\begin{array}{l}\text { Vertebral avascular risk } \\
\text { factors }\end{array}$ & $1(2)$ & $1(2)$ & 0.563 \\
$\begin{array}{l}\text { Thoracolumbar levels } \\
\text { (T11-L2) }\end{array}$ & $17(81.0 \%)$ & $17(68.0 \%)$ & 0.319 \\
Fracture severity (>25\%) & $10(47.6 \%)$ & $9(36.0 \%)$ & 0.425 \\
CR (\%) & $77.94(20.26)$ & $81.11(16.83)$ & 0.861 \\
Time from injury to MRI & $39.69 \pm 64.49$ & $9.07 \pm 12.18$ & $0.041^{*}$ \\
(Days) $_{\text {LSOR (\%) }}{ }^{2}$ & $20.24 \pm 28.08$ & $9.78 \pm 19.56$ & 0.156 \\
TOR (\%) & $13.83 \pm 12.04$ & $11.57 \pm 9.25$ & 0.476 \\
\hline
\end{tabular}

${ }^{*} P<0.05$. Data number (\%) are for fracture severity, $C R$ and gender; median (IQR) for vertebral avascular risk factors; mean $\pm S D$ for other variables. $n=$ fracture number, ${ }^{a}$ Two $L 5$ segmental fracture was not included in LSOR calculation. BMI Body mass index, CR Compression rate, MRI Magnetic resonance image, $L S O R$ Lesion segmental occlusion rate, TOR Total occlusion ratio the vertebral blood supply and could not be used for predicting IVC formation.

From T10 to L4, there were pairs of segmental arteries of the vertebrae. The L5 segmental artery was the median sacral artery, which was not included in the LOSR assessment [20]. We assessed the segmental artery condition from T10 to L4 and found that segmental artery occlusion was more common in the thoracic-lumbar region. The thoracic-lumbar region is a transition zone from the thoracic region to the lumbar region that has the maximum motion range and sufferes much stress [21]. These two factors make the thoracic-lumbar region arteries prone to occlusion. Kim et al. [12] proposed that the vertebral fracture caused segmental arteries occlusion. In our study, the occlusion rate of the fracture levels was the same as the total segmental artery occlusion rate. This result indicated that vertebral fracture was not associated with segmental artery occlusion.

There were several limitations in this study. This was not a large-scale study. However, we calculated the sample size according to previous studies and considered that the sample size was enough to draw the conclusion. Another weakness was that the detection of IVC and artery occlusion was at the same time point. Hence, the influence of vertebral long-term ischemia could not be assessed. Artery occlusion without IVC formation

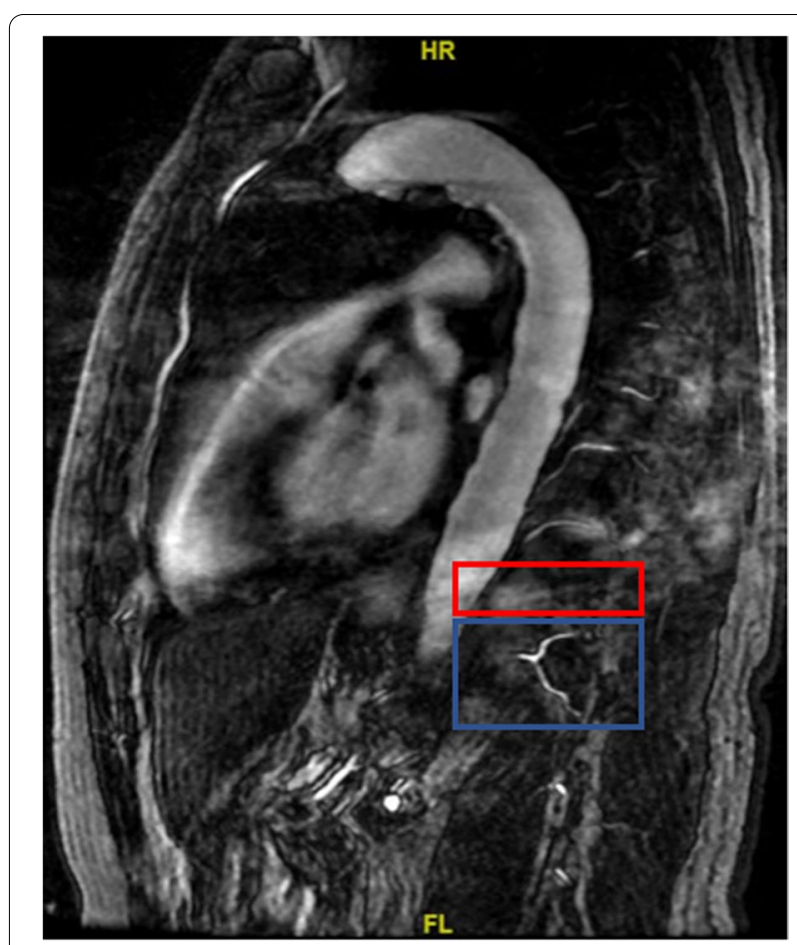

Fig. 4 Adjacent segmental artery formed collateral circulation (blue) to compensate for the ischemic level (red) 
did not indicate that IVC would not form after the MRA examination. Repeated MRI evaluations might help to further investigate the association between the IVC and artery occlusion. Because the patients included in our study received the vertebroplasty surgery, IVC formation was impossible to recheck.

\section{Conclusion}

This study provided evidence that segmental artery occlusion did not lead to the IVC. Vertebral compression fracture was not associated with segmental artery occlusion.

\section{Abbreviations}

OVCF: Osteoporosis vertebral compression fracture; IVC: Intravertebral cleft: MRI: Magnetic resonance image; AVN: Avascular necrosis; MRA: Magnetic resonance angiography; BMI: Body mass index; CR: Compression rate; LSOR: Lesion segmental occlusion rate; TOR: The total occlusion rate.

\section{Acknowledgements}

Tianyu Zhang would like to thank Yue Liao for English language editing as well as silent support for life and work.

\section{Authors' contributions}

XF and TYZ conceived the study. TYZ performed data collection, designed method, and drafted the manuscript. YK and YHW helped to perform the MRA for the patients. PXZ and DYZ revised the manuscript. XF takes responsibility for this study and applies for the funding grants. All authors have read and approved the final manuscript.

\section{Funding}

This work was supported by the Beijing Municipal Science and Technology Project [grant number D161100002816001]; This work was supported by the Ministry of Education Key Laboratory of trauma treatment and nerve regeneration [grant number BMU2019XY007-01].

\section{Availability of data and materials}

The datasets generated and analyzed during the current study are not publicly available due to the data also forms part of an ongoing study but are available from the corresponding author on reasonable request.

\section{Declarations}

\section{Ethics approval and consent to participate}

The Ethics Review Committee of Peking University People's Hospital approved this study and all methods were carried out in accordance with relevant guidelines and regulations. All the written informed consents were acquired from the patients.

\section{Consent for publication \\ Not applicable.}

\section{Competing interests}

Tianyu Zhang, Yu Kang, Yanhua Wang, Peixun Zhang, Dianyi Zhang, and Feng Xue declare that they have no conflicts of interest.

\section{Author details}

${ }^{1}$ Department of Urology, China-Japan Friendship Hospital, Beijing 100029, China. ${ }^{2}$ Department of Radiology, Peking University People's Hospital, Beijing 100044, China. ${ }^{3}$ Department of Traumatic Orthopaedics, Peking University People's Hospital, Beijing 100044, China. ${ }^{4}$ Institute of Trauma and Nerve Regeneration, Peking University People's Hospital, Beijing 100044, China.
Received: 12 February 2021 Accepted: 24 January 2022

Published online: 31 January 2022

\section{References}

1. Huang YS, Hao DJ, Feng H, Zhang HP, He SM, Ge CY, et al. Comparison of percutaneous Kyphoplasty and bone cement-augmented short-segment pedicle screw fixation for management of KÃ $1 / 4 \mathrm{mmell}$ disease. Med Sci Monit. 2018;24:1072-9. https://doi.org/10.12659/msm.905875.

2. Lu W, Wang L, Xie C, Teng Z, Han G, Shi R, et al. Analysis of percutaneous kyphoplasty or short-segmental fixation combined with vertebroplasty in the treatment of Kummell disease. J Orthop Surg Res. 2019;14(1):311. https://doi.org/10.1186/s13018-019-1358-8.

3. Huang YS, Hao DJ, Wang XD, Sun HH, Du JP, Yang JS, et al. Long-segment or bone cement-augmented short-segment fixation for Kummell disease with neurologic deficits? A comparative cohort study. World Neurosurg. 2018;116:e1079-86. https://doi.org/10.1016/j.wneu.2018.05.171.

4. Zhang TY, Zhang PX, Xue F, Zhang DY, Jiang BG. Risk factors for cement leakage and nomogram for predicting the intradiscal cement leakage after the vertebra augmented surgery. BMC Musculoskelet Disord. 2020;21(1):792. https://doi.org/10.1186/s12891-020-03810-4.

5. Yu W, Liang YZ, Qiu T, Ye L, Huang X, Jiang X. Risk factors for recollapse of the augmented vertebrae after percutaneous vertebroplasty for osteoporotic vertebral fractures with intravertebral vacuum cleft. Medicine. 2017;96(2):e5675. https://doi.org/10.1097/MD.0000000000005675.

6. Zhang T, Wang Y, Zhang P, Xue F, Zhang D, Jiang B. What are the risk factors for adjacent vertebral fracture after vertebral augmentation? A Metaanalysis of published studies. Global Spine J. 2020:2192568220978223. https://doi.org/10.1177/2192568220978223.

7. Libicher M, Appelt A, Berger I, Baier M, Meeder P, Grafe I, et al. The intravertebral vacuum phenomen as specific sign of osteonecrosis in vertebral compression fractures: results from a radiological and histological study. Eur Radiol. 2007;17(9):2248-52.

8. Armingeat T, Pham T, Legre $V$, Lafforgue P. Coexistence of intravertebral vacuum and intradiscal vacuum. Joint Bone Spine. 2006;73(4):428-32. https://doi.org/10.1016/j.jbspin.2005.10.011.

9. He D, Yu W, Chen Z, Li L, Zhu K, Fan S. Pathogenesis of the intravertebral vacuum of Kummell's disease. Exp Therapeutic Med. 2016;12(2):879-82. https://doi.org/10.3892/etm.2016.3369.

10. Kim HS, Kim SH, Ju Cl, Kim SW, Lee SM, Shin H. The role of bone cement augmentation in the treatment of chronic symptomatic osteoporotic compression fracture. J Korean Neurosurg Soc. 2010;48(6):490-5. https:// doi.org/10.3340/jkns.2010.48.6.490.

11. Lin WC, Chen HL, Lu CH, Wang HC, Wu RW, Cheng YF, et al. Dynamic contrast-enhanced magnetic resonance imaging for evaluating intraosseous cleft formation in patients with osteoporotic vertebral compression fractures before vertebroplasty. Spine (Phila Pa 1976). 2011;36(15):1244-50. https://doi.org/10.1097/BRS.0b013e3181eb9b6c.

12. Kim YC, Kim YH, Ha KY. Pathomechanism of intravertebral clefts in osteoporotic compression fractures of the spine. Spine J. 2014;14(4):659-66. https://doi.org/10.1016/j.spinee.2013.06.106.

13. Dupuy DE, Palmer WE, Rosenthal DI. Vertebral fluid collection associated with vertebral collapse. AJR Am J Roentgenol. 1996;167(6):1535-8. https://doi.org/10.2214/ajr.167.6.8956592.

14. Braunstein V, Sprecher CM, Gisep A, Benneker L, Yen K, Schneider E, et al. Long-term reaction to bone cement in osteoporotic bone: new bone formation in vertebral bodies after vertebroplasty. J Anat. 2008;212(5):697701. https://doi.org/10.1111/j.1469-7580.2008.00883.x.

15. Kurunlahti M, Karppinen J, Haapea M, Niinimäki J, Autio R, Vanharanta $\mathrm{H}$, et al. Three-year follow-up of lumbar artery occlusion with magnetic resonance angiography in patients with sciatica: associations between occlusion and patient-reported symptoms. Spine (Phila Pa 1976). 2004;29(16):1804-8; discussion 1809. https://doi.org/10.1097/01.brs. 0000134576.77709 .64$.

16. Shein-Chung Chow JS, Wang H, Lokhnygina Y. Sample size calculations in clinical research, vol 4.7. Third Edition. Taylor \& Francis Group, Boca Raton; 2018.

17. Formica M, Zanirato A, Cavagnaro L, Basso M, Felli L. What is the current evidence on vertebral body osteonecrosis?: a systematic review of the literature. Asian Spine J. 2018;12(3):586-99. 
18. Kauppila LI. Prevalence of stenotic changes in arteries supplying the lumbar spine. A postmortem angiographic study on 140 subjects. Ann Rheum Dis. 1997;56(10):591-5. https://doi.org/10.1136/ard.56.10.591.

19. Nambu K, Kawahara N, Kobayashi T, Murakami H, Ueda Y, Tomita K. Inter ruption of the bilateral segmental arteries at several levels: influence on vertebral blood flow. Spine (Phila Pa 1976). 2004;29(14):1530-4. https:// doi.org/10.1097/01.brs.0000131420.32770.06.

20. Tezuka F, Sakai T, Nishisho T, Takata Y, Higashino K, Takao S, et al. Variations in arterial supply to the lower lumbar spine. Eur Spine J. 2016;25(12):4181-7. https://doi.org/10.1007/s00586-016-4427-2.

21. Heo DH, Chin DK, Yoon YS, Kuh SU. Recollapse of previous vertebral compression fracture after percutaneous vertebroplasty. Osteoporos Int 2009;20(3):473-80. https://doi.org/10.1007/s00198-008-0682-3.

\section{Publisher's Note}

Springer Nature remains neutral with regard to jurisdictional claims in published maps and institutional affiliations.

- fast, convenient online submission

- thorough peer review by experienced researchers in your field

- rapid publication on acceptance

- support for research data, including large and complex data types

- gold Open Access which fosters wider collaboration and increased citations

- maximum visibility for your research: over $100 \mathrm{M}$ website views per year

At BMC, research is always in progress.

Learn more biomedcentral.com/submissions 